\title{
Trinuclear first row transition metal complexes of a hexapyridyl, trialkoxy 1,3,5-triarylbenzene ligand $\dagger$
}

\author{
Emily Y. Tsui, $₫$ Jacob S. Kanady, $\ddagger$ Michael W. Day and Theodor Agapie* \\ Received 16th December 2010, Accepted 14th February 2011 \\ DOI: $10.1039 / \mathrm{c0cc05608a}$
}

Trinuclear complexes of $\mathrm{Mn}^{\mathrm{II}}, \mathrm{Fe}^{\mathrm{II}}, \mathrm{Co}^{\mathrm{II}}, \mathrm{Ni}^{\mathrm{II}}, \mathrm{Cu}^{\mathrm{II}}$, and $\mathrm{Zn}^{\mathrm{II}}$ were synthesized using a ligand architecture based upon a 1,3,5triarylbenzene core decorated with six pyridines and three alkoxide moieties. Characterization via X-ray diffraction, NMR, and magnetism studies is discussed.

The active sites of several enzymes involved in dioxygen chemistry (laccase, ascorbate oxidase, the oxygen evolving center of photosystem II) display three or more first row transition metal centers. ${ }^{1}$ Synthetic catalysts for water oxidation are also proposed to be multinuclear. ${ }^{2}$

In continued efforts to rationally design multinucleating scaffolds, a 1,3,5-triarylbenzene framework was utilized to hold three multidentate binding sites near each other. 1,3,5-tris(2-(di(2-pyridyl)hydroxymethyl)phenyl)benzene $\left(\mathrm{H}_{3} \mathrm{~L}\right.$, Scheme 1) is accessible in two steps from commercially available starting materials. ${ }^{3}$ Trinuclear copper complexes supported by framework $\mathrm{L}$ have been synthesized containing a conserved $\mathrm{Cu}_{3}(\mu-\mathrm{OR})_{3}$ central moiety; varying the capping anions from halides, phosphate, tetrafluoroborate, and triflate causes subtle structural changes that affect the magnetism of these complexes. ${ }^{3}$

Protonated and deprotonated dipyridylhydroxymethyl moieties are known to exhibit an array of coordination modes, from tridentate $\mathrm{N}, \mathrm{O}, \mathrm{N}$ coordination of a single metal center to

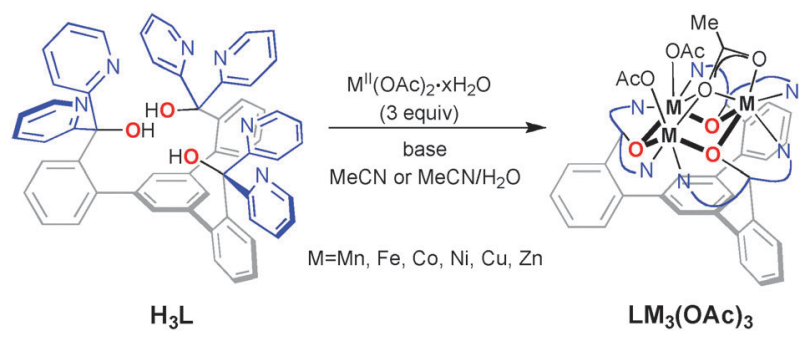

Scheme 1 Synthesis of first row divalent trinuclear metal complexes with deprotonated $\mathrm{H}_{3} \mathrm{~L}$. Acetate binding mode is variable (see text).

Department of Chemistry and Chemical Engineering, California Institute of Technology, 1200 E. California Blvd MC

127-72, Pasadena CA,USA.E-mail: agapie@caltech.edu

$\dagger$ Electronic supplementary information (ESI) available: Synthetic and crystallographic details. CCDC 777599, 787163 and 803592-803595. For ESI and crystallographic data in CIF or other electronic format see DOI: $10.1039 / \mathrm{c} 0 \mathrm{cc} 05608 \mathrm{a}$

$\ddagger$ E.Y.T. and J.S.K. contributed equally to this work.

more complicated bridging patterns of up to three metals. ${ }^{4}$ Although the $\mathrm{M}_{3}^{\mathrm{II}}(\mu-\mathrm{OR})_{3}$ structural motif is commonly found in higher nuclearity clusters in complexes of $2,2^{\prime}$ dipyridylketone $^{4}$ and as part of self-assembled tetranuclear clusters such as cubanes ${ }^{5}$ and defective dicubanes, ${ }^{6}$ the motif is less common in trinuclear complexes. ${ }^{7}$ To further investigate the metal coordination potential of $\mathrm{H}_{3} \mathrm{~L}$ and its control over cluster nuclearity, trinuclear complexes of L containing other first row transition metals were targeted.

Metallation studies were initiated with the acetate salts of the first-row metals $\mathrm{Mn}^{\mathrm{II}}, \mathrm{Fe}^{\mathrm{II}}, \mathrm{Co}^{\mathrm{II}}, \mathrm{Ni}^{\mathrm{II}}, \mathrm{Cu}^{\mathrm{II}}$, and $\mathrm{Zn}^{\mathrm{II}}$ in the presence of base. Addition of three equivalents of solid $\mathrm{M}^{\mathrm{II}}(\mathrm{OAc})_{2} \cdot x \mathrm{H}_{2} \mathrm{O}$ to a suspension of $\mathrm{H}_{3} \mathrm{~L}$ in acetonitrile or a mixture of acetonitrile-water followed by three equivalents of a base such as sodium hydroxide or triethylamine resulted in complete dissolution of insoluble materials within $12 \mathrm{~h}$. Analytically pure crystals were obtained by vapor diffusion of diethyl ether into dichloromethane or chloroform solutions of the reaction products.

Single crystal X-ray diffraction (XRD) studies demonstrate the trinucleating nature of the deprotonated $\mathrm{H}_{3} \mathrm{~L}$ framework to give complexes generally formulated as $\mathrm{LM}_{3}(\mathrm{OAc})_{3}$ (Fig. 1a). The three metal centers are bridged by three alkoxides forming a six membered ring, and the pendant pyridines coordinate with the two pyridines of each dipyridyl moiety bound to adjacent metal centers. The coordination environment is completed by acetate counterions.

The $\mathrm{LM}_{3}$ core displays pseudo- $C_{3}$ symmetry induced by a twist of each dipyridylmethoxide arm. This binding mode renders the two pyridines of each arm different, which is reflected in variations in the $\mathrm{M}-\mathrm{N}$ bond lengths (Table 1). The $\mathrm{M}-\mathrm{O}$ (alkoxide) bonds are also differentiated albeit less than the $\mathrm{M}-\mathrm{N}$ bonds - the largest difference observed is about $0.05 \AA$. The elongated $\mathrm{M}-\mathrm{N}$ bonds correspond to the three pyridines trans to alkoxide ligands. The pyridines located below the plane of the three metals and displaying shorter $\mathrm{M}-\mathrm{N}$ distances are roughly trans to the bridging acetates. $\mathrm{M}-\mathrm{O}$ (alkoxide) bonds trans to acetates are slightly shorter than those trans to pyridines. These variations may be caused by the larger trans influences of pyridine and alkoxide $v s$. acetate, but distortions caused by steric strain in the ligand framework cannot be ruled out. Consistent with the increase in the ionic radius, the metal-ligand distances increase from $\mathrm{Ni}$ to $\mathrm{Mn}$ and the $\mathrm{M}-\mathrm{M}$ distances increase from 3.182(4) $\AA$ for Ni to 3.415(1)-3.464(1) $\AA$ for Mn. The ligand 


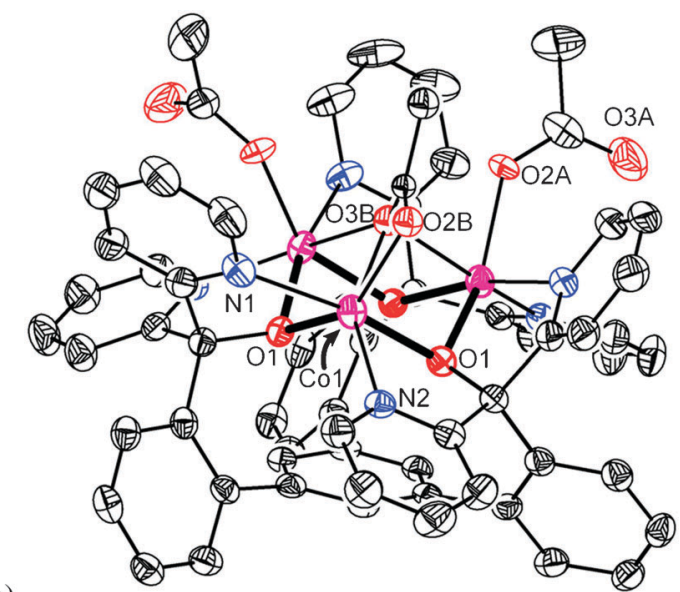

a)

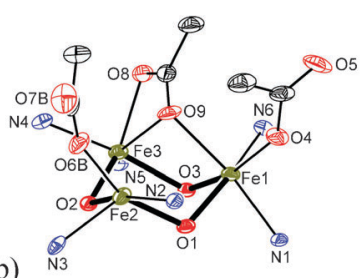

c)

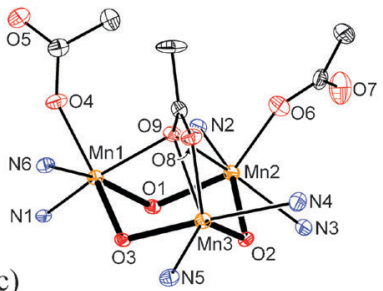

Fig. 1 (a) Solid-state structure of $\mathrm{LCo}_{3}(\mathrm{OAc})_{3}$. Coordination environments of (b) $\mathrm{LFe}_{3}(\mathrm{OAc})_{3}$ and (c) $\mathrm{LMn}_{3}(\mathrm{OAc})_{3}$ taken from the solid-state structures. The $\mathrm{M}^{\mathrm{II}}{ }_{3}(\mu-\mathrm{OR})_{3}$ structural motif is in bold; hydrogen atoms and solvent are not shown for clarity.

Table 1 Metal-metal and average metal-nitrogen distances

\begin{tabular}{llll}
\hline Compound & $\begin{array}{l}\text { M-N trans to } \\
\text { alkoxide }(\AA)\end{array}$ & $\begin{array}{l}\text { M-N trans to } \\
\text { acetate }(\AA)\end{array}$ & M-M (®) \\
\hline $\mathrm{LMn}_{3}(\mathrm{OAc})_{3}$ & $2.336(3)$ & $2.232(6)$ & $3.415(1)-3.464(1)$ \\
$\mathrm{LFe}_{3}(\mathrm{OAc})_{3}$ & $2.232(3)$ & $2.150(3)$ & $3.238(6)-3.456(6)$ \\
$\mathrm{LCo}_{3}(\mathrm{OAc})_{3}$ & $2.213(2)$ & $2.091(2)$ & $3.228(2)$ \\
$\mathrm{LNi}_{3}(\mathrm{OAc})_{3}$ & $2.127(3)$ & $2.037(3)$ & $3.182(4)$ \\
$\mathrm{LCu}_{3}(\mathrm{OAc})_{3}$ & $2.027(5)$ & $2.081(5)$ & $3.1822(7)-3.3282(7)$ \\
$\mathrm{LZn}_{3}(\mathrm{OAc})_{3}$ & $2.229(7)$ & $2.056(7)$ & $3.1975(9)-3.4199(9)$ \\
\hline
\end{tabular}

framework accommodates the different size metals by allowing for twist around the aryl-aryl bonds and of the $\mathrm{C}-\mathrm{O}$ vector $v s$. the plane of the pendant arene.

Systematically changing the nature of the metal centers from $\mathrm{Mn}^{\mathrm{II}}$ to $\mathrm{Zn}^{\mathrm{II}}$ does not disrupt the trinuclear core, but changes the binding mode of the acetates. Three capping acetates are present for $\mathrm{LM}_{3}(\mathrm{OAc})_{3}(\mathrm{M}=\mathrm{Mn}-\mathrm{Ni})$; two acetates bind in monodentate and one in bidentate fashion. The bidentate acetate bridges two or three metal centers via a $\mu_{2^{-}}$or $\mu_{3}$-oxygen atom. For $\mathrm{M}=\mathrm{Cu}$ and $\mathrm{Zn}$, single crystal XRD studies show two acetates bound to the trimetallic core (see ESI $\dagger$ ). However, a third outer sphere acetate required for charge balance could not be located due to disorder. This change in coordination mode may be due to the smaller size of $\mathrm{Cu}^{\mathrm{II}}$ and $\mathrm{Zn}^{\mathrm{II}}$ hindering the binding of a third acetate.

${ }^{1} \mathrm{H}$ NMR spectroscopy and mass spectrometry studies confirm that the trinuclear cores of the complexes are maintained in solution. The ${ }^{1} \mathrm{H}$ NMR spectra of $\mathrm{LM}_{3}(\mathrm{OAc})_{3}(\mathrm{M}=\mathrm{Fe}-\mathrm{Zn})$ display fourteen resonances, with chemical shifts between -20 and 160 ppm for the paramagnetic species. ${ }^{8}$ Thirteen signals correspond to protons on framework L, consistent with the pseudo- $C_{3}$-geometry observed in the solid-state. The single peak assigned to the acetate counterions is indicative of fluxional processes that exchange the capping ligands on the NMR time scale.

The magnetism of triangular clusters has been studied in the context of spin frustration and molecular magnets. ${ }^{9}$ Although several alkoxo-bridged $\mathrm{Ni}_{3}{ }_{3}$ and $\mathrm{Cu}^{\mathrm{II}}{ }_{3}$ complexes have been studied, ${ }^{7 d, 10}$ there have been fewer investigations of $\mathrm{Mn}_{3}^{\mathrm{II}}$, $\mathrm{Fe}^{\mathrm{II}}{ }_{3}$, and $\mathrm{Co}_{3}{ }_{3}$ cores. Triangular clusters of manganese and iron more commonly contain higher oxidation state metal centers. ${ }^{11}$ The present $\mathrm{LM}_{3}(\mathrm{OAc})_{3}$ family provides an opportunity to systematically study the magnetic interactions of several divalent transition metals in a single trinuclear system, allowing for better understanding of the magnetostructural characteristics of trinuclear complexes.

Magnetic susceptibility measurements were performed on powdered crystalline samples of $\mathrm{LM}_{3}(\mathrm{OAc})_{3}(\mathrm{M}=\mathrm{Mn}, \mathrm{Fe}$, $\mathrm{Co}, \mathrm{Ni}, \mathrm{Cu})$ in the temperature range 4-300 $\mathrm{K}$. At room temperature, the $\chi_{\mathrm{M}} T$ values approach $12.0,9.0,6.7,3.3$, and $1.0 \mathrm{~cm}^{3} \mathrm{~K} \mathrm{~mol}^{-1}$, respectively (Fig. 2). The difference between these and the spin-only values may be due to spin-orbit coupling and population of excited states. ${ }^{12}$ Upon cooling, the $\chi_{\mathrm{M}} T$ values decrease gradually and then drop sharply below $40 \mathrm{~K}$, indicating the presence of antiferromagnetic exchange interactions. With the exception of the $\chi_{\mathrm{M}} T$ values of $\mathrm{LCu}_{3}(\mathrm{OAc})_{3}$, which approach a plateau near the expected value for the spin-only $S=1 / 2$ state (ca. $0.4 \mathrm{~cm}^{3} \mathrm{~K} \mathrm{~mol}^{-1}$ ), the $\chi_{\mathrm{M}} T$ plots do not approach obvious limiting values at $4 \mathrm{~K}$.

To determine the magnitude of exchange between neighboring metal centers, the magnetic behavior of the compounds was analyzed using the isotropic spin Hamiltonian [eqn (1)] considering the two exchange pathways of an isosceles triangular arrangement. Application of the Van Vleck equation according to the Kambe vector method ${ }^{13}$ yields the magnetic susceptibility equation [eqn (2)].

$$
H=-2 J\left[\left(S_{1} S_{2}\right)+\left(S_{2} S_{3}\right)\right]-2 J_{13}\left(S_{3} S_{1}\right)
$$

$\chi_{M}=\frac{N_{A} \beta^{2} g^{2}}{3 k T}\left(\frac{\sum S^{\prime}\left(S^{\prime}+1\right)\left(2 S^{\prime}+1\right) \Omega\left(S^{\prime}\right) \exp \left(-W\left(S^{\prime}\right) / k T\right)}{\sum\left(2 S^{\prime}+1\right) \Omega\left(S^{\prime}\right) \exp \left(-W\left(S^{\prime}\right) / k T\right)}\right)$

The Curie-Weiss parameter $\theta$ was included to account for possible intermolecular interactions. ${ }^{14}$

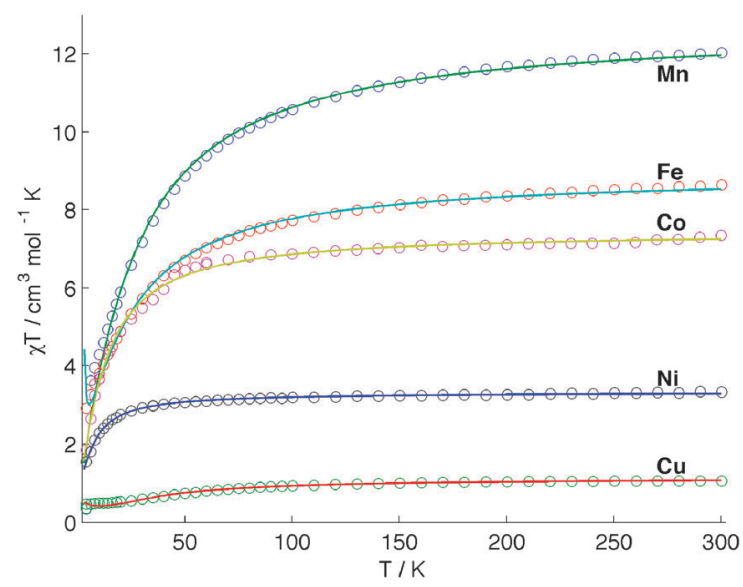

Fig. 2 Plots of $\chi_{M} T$ vs. T. Solid lines show the best fits obtained. 
Table 2 Magnetic susceptibility parameters ${ }^{17}$

\begin{tabular}{lllll}
\hline Compound & $J\left(\mathrm{~cm}^{-1}\right)$ & $g$ & $\theta(\mathrm{K})$ & $R\left(\times 10^{-4}\right)$ \\
\hline $\mathrm{LMn}_{3}(\mathrm{OAc})_{3}$ & -1.1 & 1.97 & 0.53 & 10 \\
$\mathrm{LFe}_{3}(\mathrm{OAc})_{3}$ & -1.4 & 1.99 & 2.35 & 1.6 \\
$\mathrm{LCo}_{3}(\mathrm{OAc})_{3}$ & -1.2 & 2.30 & 0.23 & 1.9 \\
$\mathrm{LNi}_{3}(\mathrm{OAc})_{3}$ & -1.2 & 2.11 & 0.74 & 0.4 \\
$\mathrm{LCu}_{3}(\mathrm{OAc})_{3}$ & -13.7 & 2.01 & 0.75 & 12 \\
\hline
\end{tabular}

The fits were not appreciably improved when modeling two $J$ values instead of one; as a result, the magnetism data were simulated for an equilateral triangle arrangement of spins, corresponding to the approximate $C_{3}$-symmetry of the $\mathrm{M}_{3}(\mathrm{OR})_{3}$ cores (without acetates). ${ }^{15}$ It should be noted that the modeled parameters approximate the spins of each compound as isotropic and do not account for the lowered symmetry of each complex induced by the coordinated acetates. Nevertheless, the simulated magnetic susceptibility parameters (Table 2 ) show a good fit to the experimental data $\left(R \sim 10^{-4}\right)$. In accordance with the $\chi_{\mathrm{M}} T$ plots, the simulated parameters show that compounds $\mathrm{LM}_{3}(\mathrm{OAc})_{3}$ display weak antiferromagnetic exchange coupling (Table 2). Except for $\mathrm{LCu}_{3}(\mathrm{OAc})_{3}\left(J=-13.7 \mathrm{~cm}^{-1}\right)$, the best fits were obtained with $|J|<2 \mathrm{~cm}^{-1}$. Although the ground states are predicted to be $S=0$ or $S=1 / 2$ for an equilateral triangle of antiferromagnetically coupled ions, such small $J$ values indicate that higher spin states are thermally populated even at low temperatures. ${ }^{16}$ For these complexes, the presence of spin equilibria between these states is consistent with the observation that no limiting values of $\chi_{\mathrm{M}} T$ are reached at $4 \mathrm{~K}$.

Due to the presence of multiple types of bridging ligands, it is difficult to definitively assign the exchange pathways in these $\mathrm{LM}_{3}(\mathrm{OAc})_{3}$ complexes. ${ }^{18}$ Since there are few alkoxo-bridged trinuclear complexes containing metals other than $\mathrm{Cu}^{\mathrm{II}}$ - and none with $\mathrm{Fe}^{\mathrm{II}}$ to our knowledge-there is yet no clear correlation between the $J$ constants and common structural parameters such as $\mathrm{M}-\mathrm{M}$ distances or $\mathrm{M}-\mathrm{O}-\mathrm{M}$ angles. ${ }^{19}$ Previously studied acetate-bridged trinuclear clusters of divalent metals have been shown to have similar intramolecular exchange interactions. ${ }^{20}$ Alkoxo- and phenoxobridged tricobalt(II), trinickel(II), and triiron(III) clusters all show small antiferromagnetic coupling. ${ }^{7 e, 21}$ While there are no examples of $\mathrm{Mn}^{\mathrm{II}}$ bridged by alkoxides, amido-bridged ${ }^{22}$ or carboxylate-bridged ${ }^{23} \mathrm{Mn}^{\text {II }}$ clusters also demonstrated antiferromagnetic coupling of magnitudes similar to $\mathrm{LMn}_{3}(\mathrm{OAc})_{3}$.

In summary, the trinucleating ligand described above is a scaffold capable of supporting different first-row transition metals in a conserved trinuclear core geometry. These trimetallic complexes have been structurally and spectroscopically characterized. Current efforts are underway to explore multielectron reactivity and small molecule activation with these clusters.

We thank Lawrence M. Henling for crystallographic assistance. We are grateful to Caltech, Chemistry Department Dow Fellowship (JSK), and NSF GRFP (EYT) for funding. The Bruker KAPPA APEXII X-ray diffractometer was purchased via an NSF CRIF:MU award to Caltech, CHE-0639094. SQUID data were collected at the MMRC of the Beckman Institute of the California Institute of Technology.

\section{Notes and references}

1 (a) R. H. Holm, P. Kennepohl and E. I. Solomon, Chem. Rev., 1996, 96, 2239-2314; (b) J. P. McEvoy and G. W. Brudvig, Chem. Rev., 2006, 106, 4455-4483.

2 (a) M. W. Kanan, J. Yano, Y. Surendranath, M. Dinca, V. K. Yachandra and D. G. Nocera, J. Am. Chem. Soc., 2010, 132, 13692-13701; (b) M. Risch, V. Khare, I. Zaharieva, L. Gerencser, P. Chernev and H. Dau, J. Am. Chem. Soc., 2009, 131, 6936-6937.

3 E. Y. Tsui, M. W. Day and T. Agapie, Angew. Chem., Int. Ed., 2011, 50, 1668-1672.

4 T. C. Stamatatos, C. G. Efthymiou, C. C. Stoumpos and S. P. Perlepes, Eur. J. Inorg. Chem., 2009, 3361-3391.

5 G. S. Papaefstathiou, A. Escuer, F. A. Mautner, C. Raptopoulou, A. Terzis, S. P. Perlepes and R. Vicente, Eur. J. Inorg. Chem., 2005, 879-893.

6 (a) Z. E. Serna, L. Lezama, M. K. Urtiaga, M. I. Arriortua, M. G. Barandika, R. Cortés and T. Rojo, Angew. Chem., Int. Ed., 2000, 39, 344-347; (b) C. G. Efthymiou, C. P. Raptopoulou, A. Terzis, R. Boĉa, M. Korabic, J. Mrozinski, S. P. Perlepes and E. G. Bakalbassis, Eur. J. Inorg. Chem., 2006, 2236-2252.

7 (a) B. F. Abrahams, T. A. Hudson and R. Robson, Chem.-Eur. J., 2006, 12, 7095-7102; (b) R. D. Köhn, M. Haufe, G. Kociok-Köhn and A. C. Filippou, Inorg. Chem., 1997, 36, 6064-6069; (c) S. G. Telfer, R. Kuroda, J. Lefebvre and D. B. Leznoff, Inorg. Chem., 2006, 45, 4592-4601; (d) M. Kodera, Y. Tachi, T. Kita, H. Kobushi, Y. Sumi, K. Kano, M. Shiro, M. Koikawa, T. Tokii, M. Ohba and H. Okawa, Inorg. Chem., 2000, 39, 226-234; (e) E. Labisbal, L. Rodríguez, O. Souto, A. Sousa-Pedrares, J. A. García-Vázquez, J. Romero, A. Sousa, M. Yáñez, F. Orallo and J. A. Real, Dalton Trans., 2009, 8644-8656.

8 The resonances in the ${ }^{1} \mathrm{H}$ NMR spectrum of $\mathrm{LMn}_{3}(\mathrm{OAc})_{3}$ were broadened such that only four resonances were visible.

9 (a) L.-L. Wang, Y.-M. Sun, Z.-Y. Yu, Z.-N. Qi and C.-B. Liu, J. Phys. Chem. A, 2009, 113, 10534-10539; (b) S. Ferrer, F. Lloret, I. Bertomeu, G. Alzuet, J. Borrás, S. García-Granda, M. LiuGonzález and J. G. Haasnoot, Inorg. Chem., 2002, 41, 5821-5830.

10 M. Inoue, C. Ikeda, Y. Kawata, S. Venkatraman, K. Furukawa and A. Osuka, Angew. Chem., Int. Ed., 2007, 46, 2306-2309.

11 A CSD search for oxygen atom-bridged trinuclear clusters with two $\mathrm{N}$-donors per metal centers resulted in only one example of a complex with three $\mathrm{Mn}^{\mathrm{II}}$ centers and no results for three $\mathrm{Fe}^{\mathrm{II}}$ centers. The remaining search results contained $\mathrm{Mn}^{\mathrm{IV}}$ and $\mathrm{Fe}^{\mathrm{III}}$ clusters.

12 R. S. Drago, Physical Methods for Chemists, Surfside Scientific Publishers, Gainesville, 1992.

13 (a) K. Kambe, J. Phys. Soc. Jpn., 1950, 5, 48-51; (b) E. Sinn, Coord. Chem. Rev., 1970, 5, 313.

14 V. H. Crawford, H. W. Richardson, J. R. Wasson, D. J. Hodgson and W. E. Hatfield, Inorg. Chem., 1976, 15, 2107-2110.

15 Magnetic susceptibility parameters were determined by minimizing $\left.R=\sum\left|\left(\chi_{M}^{T}\right)_{\mathrm{obs}}-\left(\chi_{M}\right)_{\text {calcd }}\right|^{2} / \sum\left(\chi_{M}\right)^{T}\right)_{\text {obs }}^{2}$.

16 (a) F. E. Mabbs and D. J. Machin, Magnetism and Transition Metal Complexes, Dover Publications, Inc., Mineola, 2008; (b) S. Haddadpour, H. Niedermeyer, R. Clérac and S. Dehnen, Dalton Trans., 2009, 8162-8164.

17 For $\mathrm{LMn}_{3}(\mathrm{OAc})_{3}$, the discrepancy between the expected $g$-value of 2.00 and the fitted value of 1.97 may be accounted for by small amounts of solvent in the sample detected by ${ }^{1} \mathrm{H}$ NMR spectroscopy.

18 O. Kahn, Molecular Magnetism, VCH Publishers, Inc., New York, 1993.

19 Y.-B. Jiang, H.-Z. Kou, R.-J. Wang, A.-L. Cui and J. Ribas, Inorg. Chem., 2005, 44, 709-715.

20 R. A. Reynolds, W. O. Yu, W. R. Dunham and D. Coucouvanis, Inorg. Chem., 1996, 35, 2721-2722.

21 (a) H. Adams, D. E. Fenton, L. R. Cummings, P. E. McHugh, M. Ohba, H. Okawa, H. Sakiyama and T. Shiga, Inorg. Chim. Acta, 2004, 357, 3648-3656; (b) C. Boskovic, E. Rusanov, H. Stoeckli-Evans and H. U. Güdel, Inorg. Chem. Commun., 2002, 5, 881-886.

22 J. A. Hatnean, R. Raturi, J. Lefebvre, D. B. Leznoff, G. Lawes and S. A. Johnson, J. Am. Chem. Soc., 2006, 128, 14992-14999.

23 P. Christian, G. Rajaraman, A. Harrison, M. Helliwell, J. J. W. McDouall, J. Raftery and R. E. P. Winpenny, Dalton Trans., 2004, 2550-2555. 